\title{
RUANG KOMUNITAS BERBASIS TANAMAN DI RAWA BELONG
}

\author{
Antonia Vicki Amelia ${ }^{1)}$, Suryono Herlambang ${ }^{2)}$ \\ ${ }^{1)}$ Program Studi S1 Arsitektur, Fakultas Teknik, Universitas Tarumanagara, \\ antonia.315160016@stu.untar.ac.id \\ 2) Program Studi S1 PWK, Fakultas Teknik, Universitas Tarumanagara, suryonoh@ft.untar.ac.id
}

\begin{abstract}
Abstrak
Seiring perkembangan zaman semakin banyak orang-orang terutama di kota besar yang hidup secara individual dan kurang berinteraksi secara langsung baik antarindividu, individu dengan kelompok, maupun antar kelompok. Kurangnya interaksi tersebut dilatar belakangi oleh berbagai macam hal yang salah satunya adalah tidak adanya ruang-ruang komunitas untuk tempat berkumpul, berinteraksi, atau bertukar pikiran. Plant as Connection adalah sebuah ruang komunitas yang berbasis pada tanaman yang terletak di kawasan Rawa Belong, Kebon Jeruk, Jakarta Barat, dengan tujuan menjadi konektor atau penghubung dimana individu maupun kelompok dapat berkumpul dan berinteraksi secara langsung. Dikarenakan aktivitasnya yang berbasis pada tanaman, maka proyek ini berlokasi di kawasan Rawa Belong, Jakarta Barat yang sudah dikenal sebagai kawasan tanaman hias dari zaman dahulu. Proyek ini dirancang berbasis pada tanaman karena pada kehidupan di masa depan tanaman merupakan salah satu hal penting yang akan mempengaruhi cara hidup manusia. Pengaruh tanaman pada cara hidup manusia ini sudah mulai terlihat dari kondisi saat ini dimana banyak sekali orang yang berlomba-lomba untuk merawat tanaman di rumah guna dijadikan sebagai hiasan ruangan, hobi, aktivitas di kala senggang, bahkan untuk dikonsumsi. Oleh sebab itu, kesamaan aktivitas maupun hobi ini dapat mengakibatkan munculnya komunitas baru dan menciptakan peluang adanya ruang komunitas guna mewadahi aktivitas komunitas tersebut serta meningkatkan interaksi antarindividu, individu dengan kelompok, maupun antar kelompok.
\end{abstract}

\section{Kata kunci: interaksi; ruang komunitas; tanaman}

\begin{abstract}
Along with the times, there are more and more people, especially in big cities, who live individually and have less direct interaction between individuals, individuals with groups, and between groups. This lack of interaction is motivated by a variety of things, one of which is the absence of community spaces for gathering, interacting, or exchanging ideas. Plant as Connection is a plant-based community space located in the area of Rawa Belong, Kebon Jeruk, West Jakarta, with the aim of being a connector or link where individuals and groups can gather and interact directly. Due to its plant-based activities, this project is located in the Rawa Belong area, West Jakarta which has been known as an ornamental plant area from time immemorial. This project is designed based on plants because in the future life, plant is one of the important things that will affect the way of human life. The influence of plants on the human life has begun to be seen from the current conditions where many people are competing to planting at home to be used as room decoration, hobbies, leisure activities, even for consumption. Therefore, the similarity of activities and hobbies can lead to the emergence of new communities and create opportunities for community space to accommodate these community activities and increase interaction between individuals, individuals with groups, and between groups.
\end{abstract}

Keywords: community space; interaction; plants 


\section{PENDAHULUAN}

\section{Latar Belakang}

Dari awal peradaban sampai kapanpun manusia tidak akan pernah terlepas dari kegiatan berhuni untuk bertahan hidup. Dalam berhuni atau bertahan hidup manusia pasti membutuhkan manusia lain karena manusia adalah makhluk sosial yang tidak dapat tinggal sendiri. Oleh sebab itu, hubungan antar manusia dengan manusia lain akan menimbulkan interaksi sosial yang terjadi secara langsung atau tatap muka. Tetapi seiring perkembangan zaman interaksi sosial secara langsung semakin berkurang yang dapat disebabkan oleh berbagai macam hal.

Yang pertama adalah perkembangan gadget dan media sosial yang semakin mempengaruhi kehidupan manusia. Dalam masa kini, banyak sekali ditemui orang-orang yang berkumpul tetapi sibuk terhadap gadgetnya masing-masing. Hal ini menggambarkan bahwa hanya raga mereka yang hadir di sana tetapi jiwa mereka sibuk dengan dunianya sendiri tanpa mempedulikan orang di sekelilingnya. Yang kedua adalah kehidupan di kota besar. Saat seseorang hidup di kota besar dan padat, kebanyakan masyarakatnya tinggal jauh dari tempat mereka bekerja ataupun bersekolah yang berakibat perlunya waktu lebih untuk mencapai tempat tujuan mereka. Kebutuhan waktu yang lebih lama ini menjadikan mereka tidak memiliki waktu untuk berkumpul bersama lingkungan komunitas di sekitar mereka. Yang ketiga adalah tidak adanya ruang untuk mereka bersosialisasi atau melakukan hal bersama dengan orang yang mungkin memiliki kesamaan hobi, pekerjaan, atau latar belakang kehidupan yang sama.

Di masa depan, kemungkinan akan terjadi ikatan sosial baru diperkotaan sangatlah besar. Hal ini dapat dikarenakan munculnya hobi-bobi baru yang banyak digemari orang dan menyebabkan munculnya komunitas untuk latar belakang hobi atau kesukaan yang sama. Ikatan sosial baru ini memungkinkan mereka untuk berkumpul bersama di luar lingkungan tempat tinggal mereka dan melakukan hal-hal baru yang produktif dan mereka sukai, kemungkinan inilah yang memberikan peluang bahwa ruang komunitas akan dibutuhkan kedepannya.

\section{Tujuan}

Tujuan dari proyek yang dirancang adalah untuk memberikan ruang kepada komunitas pecinta tanaman untuk berkumpul, bertukar pikiran, belajar, serta bertemu dengan orang baru untuk saling mengenal. Selain itu, proyek ini juga bertujuan untuk mengembalikan kekerabatan antarindividu, individu dengan kelompok, atau antar kelompok untuk berkomunikasi dan berinteraksi secara langsung.

\section{Rumusan Masalah}

Ada beberapa hal yang akan dibahas dalam makalah ini yaitu bagaimana proses interaksi sosial terjadi, apa yang dimaksud dengan komunitas, dan bagaimana sebuah komunitas dapat terbentuk dalam lingkungan masyarakat.

\section{KAJIAN LITERATUR}

\section{Interaksi Sosial}

Dalam berhuni manusia tidak pernah terlepas dari interaksi dengan manusia lainnya karena pada hakikatnya manusia adalah makhluk sosial yang tidak dapat tinggal sendiri melainkan butuh manusia lain untuk berinteraksi (Ginintasasi, 2017). Menurut Soekanto interaksi sosial merupakan dasar proses sosial yang terjadi karena adanya hubungan-hubungan sosial yang dinamis mencakup hubungan antarindividu, antar kelompok, atau antarindividu dengan kelompok (Soekanto, 2000).

Para ahli komunikasi sepakat mengatakan bahwa interaksi yang baik dan ideal adalah interaksi secara langsung karena memungkinkan terjadinya interaksi dan komunikasi yang bersifat 
dinamis dan timbal balik secara langsung, sehingga mempercepat proses saling mempengaruhi dan pertukaran informasi diantara pihak-pihak yang berinteraksi di dalamnya. Dalam interaksi sosial, ada dua syarat yang harus terpenuhi yaitu adanya kontak sosial dan komunikasi. Menurut Wates dan Knevitt (1987) interaksi sosial ada tiga macam yaitu interaksi antara individu dengan individu (terjadi saat dua individu bertemu dan menyadari kehadiran pihak lain walaupun tidak melakukan kegiatan apapun), interaksi antara kelompok dengan kelompok, dan interaksi antara individu dengan kelompok.

Pada dasarnya interaksi sosial terbagi menjadi dua proses (Partowisastro, 2003), yaitu Proses asosiatif (proses asosiatif ada tiga macam kerja sama, akomodasi, dan asimilasi); Proses disosiatif (proses disosiatif dibedakan dalam tiga bentuk yaitu persaingan, kontravensi, dan pertikaian). Faktor-faktor yang mempengaruhi interaksi sosial adalah iaktor imitasi, faktor sugesti, faktor identifikasi dan simpati.

\section{Komunitas}

Dalam proses interaksi sosial dapat tercipta komunitas. Menurut George Hillery komunitas adalah hal yang dibangun dengan fisik atau lokasi geografi dan kesamaan dasar akan kesukaan atau kebutuhan (Hillery, 1955). Ahli lainnya mengatakan bahwa komunitas adalah sekelompok orang yang saling peduli satu sama lain lebih dari yang seharusnya, dimana dalam sebuah komunitas terjadi relasi pribadi yang erat antar para anggota komunitas tersebut karena adanya kesamaan interest atau values (Kertajaya, 2008). Crow dan Allan (1994) berdasarkan jenisnya, komunitas dibagi menjadi dua jenis yaitu Komunitas berdasarkan lokasi atau wilayah (tempat di mana sekumpulan orang mempunyai sesuatu yang sama secara geografis); Komunitas berdasarkan minat (sekelompok orang yang mendirikan suatu komunitas karena memiliki suatu ketertarikan dan minat yang sama misalnya agama, pekerjaan, suku, hobi, dan lain-lain).

\section{METODE}

Dalam proses penilitian, yang pertama kali dilakukan adalah mencari isu yang terjadi saat ini dan berpengaruh terhadap kehidupan manusia di masa depan. Dari pencarian tersebut ditemukan bahwa isu yang terjadi saat ini dan akan mempengaruhi kehidupan manusia di masa depan adalah semakin berkurangnya interaksi secara langsung antar manusia terutama di kota-kota besar. Setelah melakukan pencarian isu, selanjutnya yang dilakukan adalah melakukan riset terhadap penyebab munculnya isu yang diangkat dan hal apa yang dapat membantu menyelesaikannya. Dalam riset ditemukan bahwa salah satu penyebab semakin berkurangnya interaksi secara langsung adalah kurangnya ruang komunitas untuk berkumpul, sehingga muncul peluang untuk mengajukan proyek ruang komunitas.

Dari proyek yang ditentukan, selanjutnya dilakukan pencarian tapak yang memiliki latar belakang atau ciri khas kawasan tertentu dan ditemukan kawasan Rawa Belong di Kecamatan Kebon Jeruk, Jakarta Barat dengan latar belakang kawasan yaitu kawasan tanaman hias. Setelah pencarian kawasan baru dilakukan proses merancang dengan metode kontekstual karena fungsi bangunan sebagai ruang komunitas diharapkan dapat menyatu dengan lingkungan sekitarnya.

\section{DISKUSI DAN HASIL}

\section{Lokasi Tapak}

Lokasi tapak berada di jalan Qrisdoren II, Kel. Sukabumi Utara, Kec. Kebon Jeruk, Jakarta Barat dengan peraturan sebagai berikut:

$\begin{array}{ll}\text { KDB } & : 50 \% \\ \text { KDH } & : 30 \% \\ \text { KLB } & : 2 \\ \text { KB } & : 4 \\ \text { KTB } & : 55 \%\end{array}$




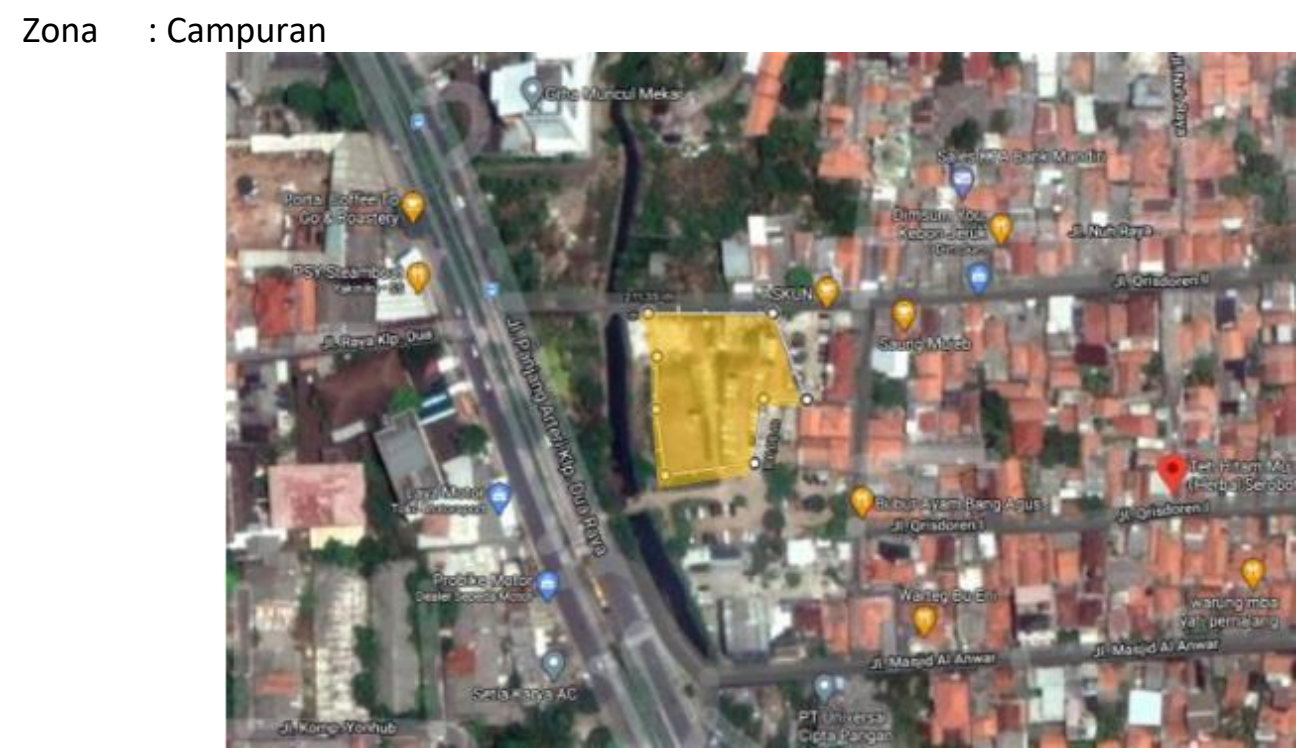

Gambar 1. Peta lokasi tapak

Sumber: Google maps 2020

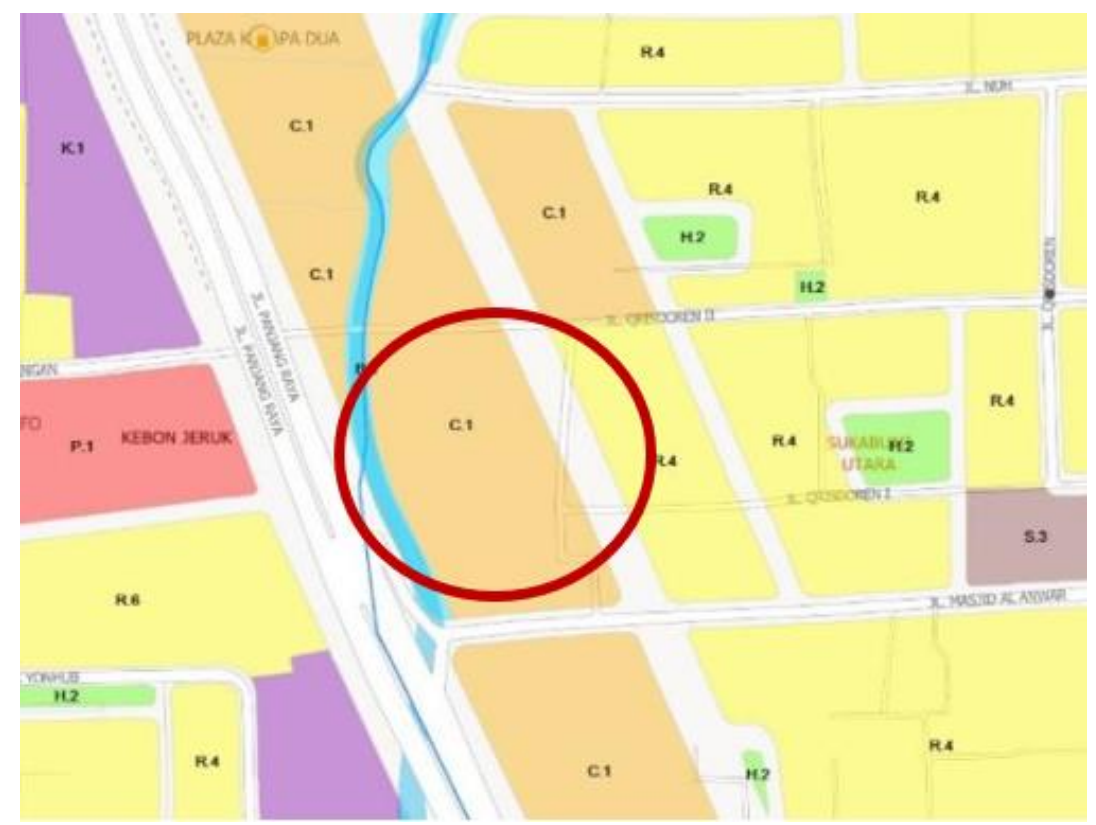

Gambar 2. Peta zonasi tapak

Sumber: jakartasatu.jakarta.go.id

\section{Aktivitas dan Program}

Berdasarkan kondisi lingkungan sekitar tapak yang memiliki latar belakang sebagai kawasan tanaman hias serta fungsi bangunan sebagai ruang komunitas, maka diusulkan 4 program utama yaitu area komunal, pelatihan hidroponik, pelatihan merangkai bunga, dan pelatihan tanaman obat. Program-program tersebut diusulkan dengan tujuan agar orang yang datang tidak hanya bisa berkumpul tetapi juga dapat belajar lebih banyak tentang tanaman. Selain itu, diusulkan pula fasilitas pendukung yaitu retail dan supermarket yang menjual berbagai kebutuhan bercocok tanam. Dari program-program yang ada, dirancang pembagian area sebagai berikut. 

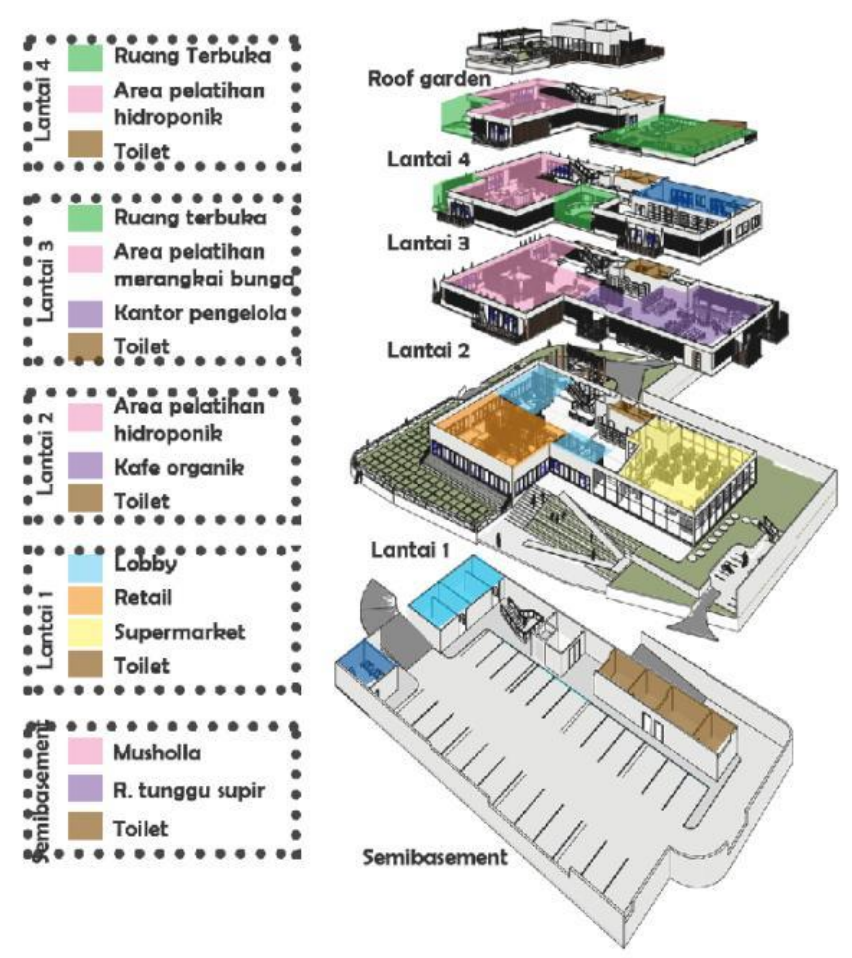

Gambar 3. Pembagian area aktivitas bangunan Sumber: Penulis, 2020

\section{Gubahan Massa}

Bentuk awal gubahan berbentuk segiempat dengan bentuk memanjang dari arah utara ke selatan sesuai dengan bentuk tapak. Bentuk dasar segiempat ini diambil dari kondisi sekitar tapak yang juga memiliki bentuk dasar segiempat. Hal ini dilakukan karena fungsi bangunan sebagai ruang komunitas diharapkan dapat berbaur dengan lingkungan sekitarnya dan bukan berdiri sendiri secara kontras dengan lingkungannya.

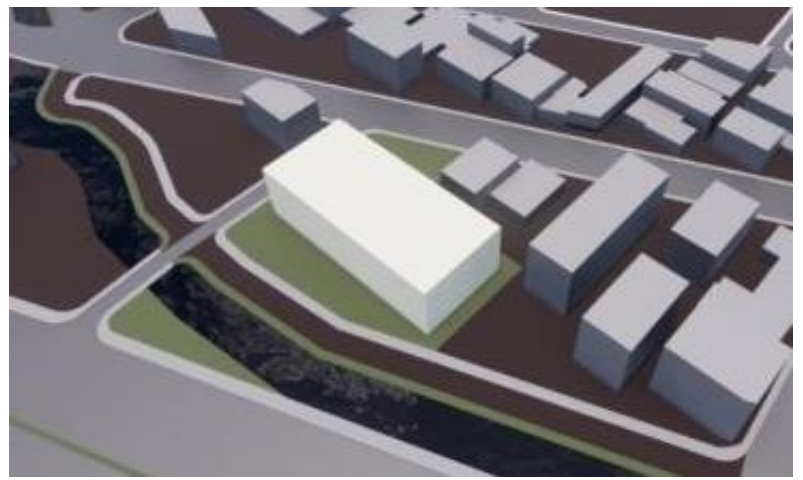

Gambar 4. Gubahan massa ke-1 Sumber: Penulis, 2020

Selanjutnya, bangunan dirancang lebih menjorok pada sisi kiri dengan tujuan memberikan kesan terbuka dan menerima kepada pengunjung yang akan datang serta memberikan sudut pandang ke arah view terbaik secara maksimal. 


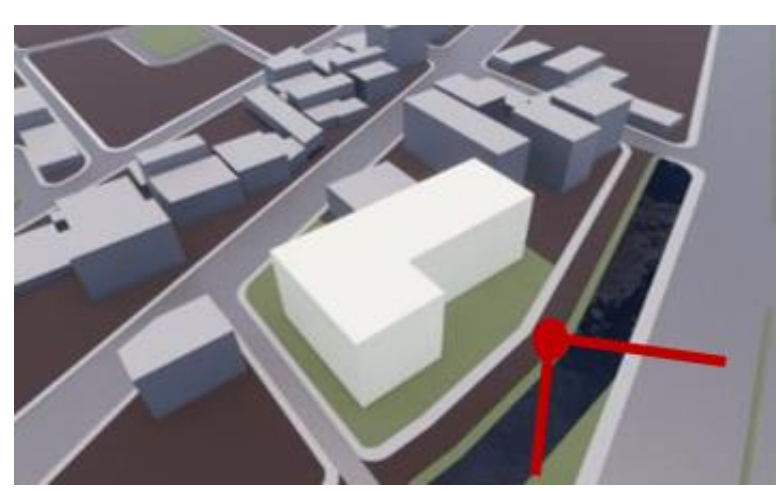

Gambar 5. Gubahan massa ke-2

Sumber: Penulis, 2020

Bangunan pada sisi kanan dirancang memiliki ketinggian yang lebih rendah karena akan digunakan sebagai taman tanaman obat serta ruang terbuka bagi para pengunjung.

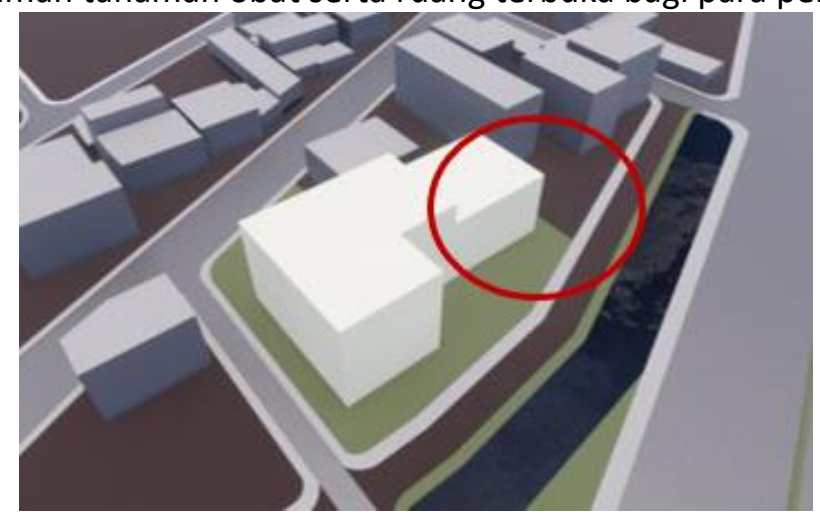

Gambar 6. Gubahan massa ke-3

Sumber: Penulis, 2020

Dikarenakan konsep bangunan yang mengutamakan hubungan ruang luar dan ruang dalam secara transparan, maka dibeberapa sisi bangunan dirancang ruang-ruang terbuka kecil.

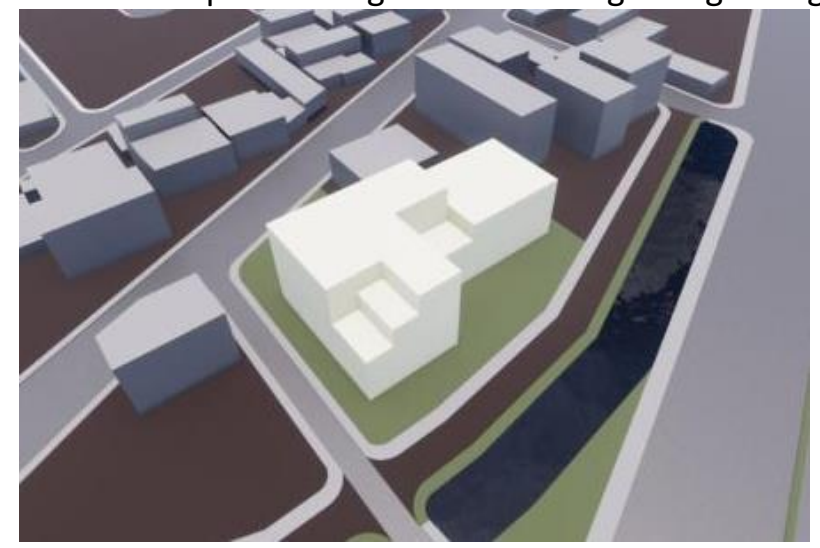

Gambar 7. Gubahan massa ke-4

Sumber: Penulis, 2020

Dibeberapa sisi bangunan dirancang balkon-balkon kecil yang berguna sebagai tambahan ruang terbuka serta memberikan tampilan tampak bangunan yang lebih menarik dan dinamis. 


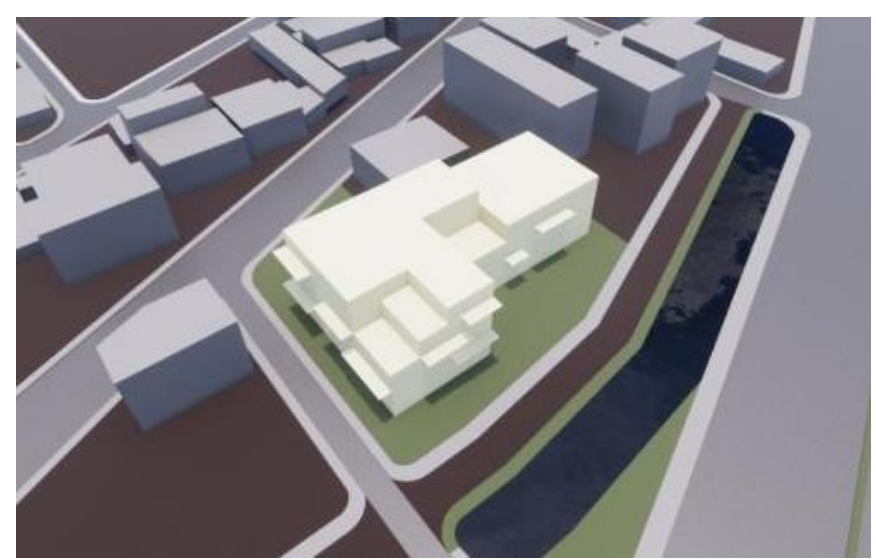

Gambar 8. Gubahan massa ke-5

Sumber: Penulis, 2020

\section{Penerapan Ide Desain pada Bangunan}

Bangunan yang dirancang memiliki fungsi sebagai ruang komunitas yang berbasis pada tanaman, sehingga bangunan dirancang dengan beberapa ide desain. Ide desain yang pertama adalah bangunan dirancang setransparan mungkin agar pengudaraan di dalam bangunan cocok untuk tanaman dan juga lebih mencerminkan ruang komunitas yang terbuka terhadap siapa saja. Oleh sebab itu, hampir seluruh sisi bangunan dirancang terbuka dan hanya diberi teralis besi serta pintu untuk keamanan bangunan.

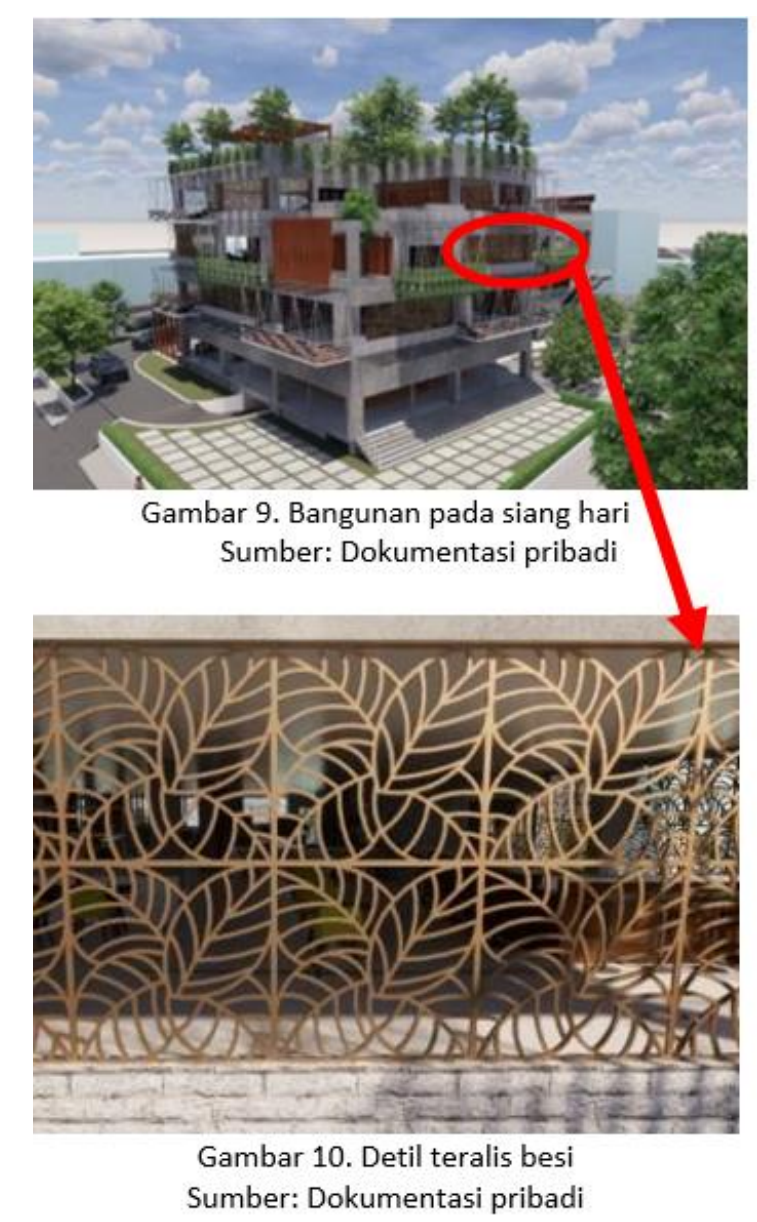




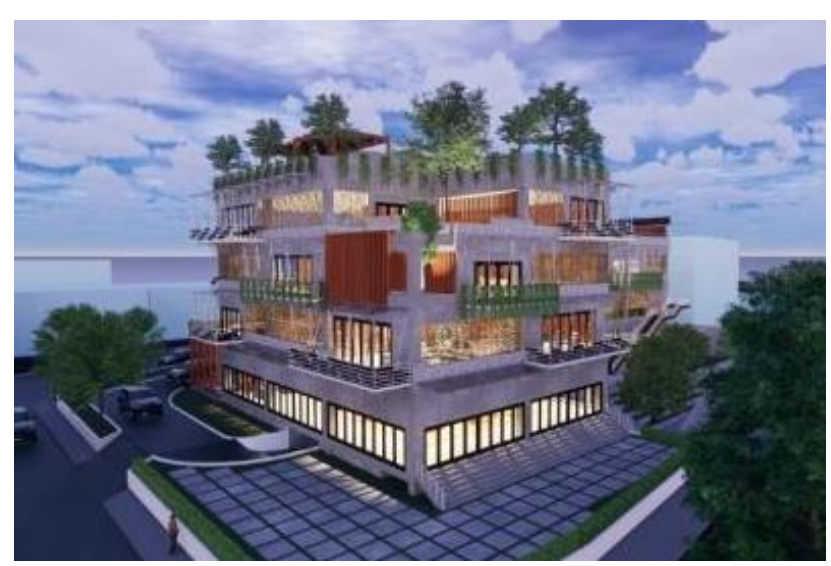

Gambar 11. Bangunan pada malam hari Sumber: Penulis, 2020

Ide desain yang kedua adalah menampilkan hubungan erat antara ruang dalam dan ruang luar. Dalam penerapannya, di beberapa sudut bangunan dirancang ruang-ruang terbuka kecil yang berguna sebagai tempat berkumpul maupun taman guna memperkuat hubungan antara ruang dalam dan ruang luar pada bangunan.

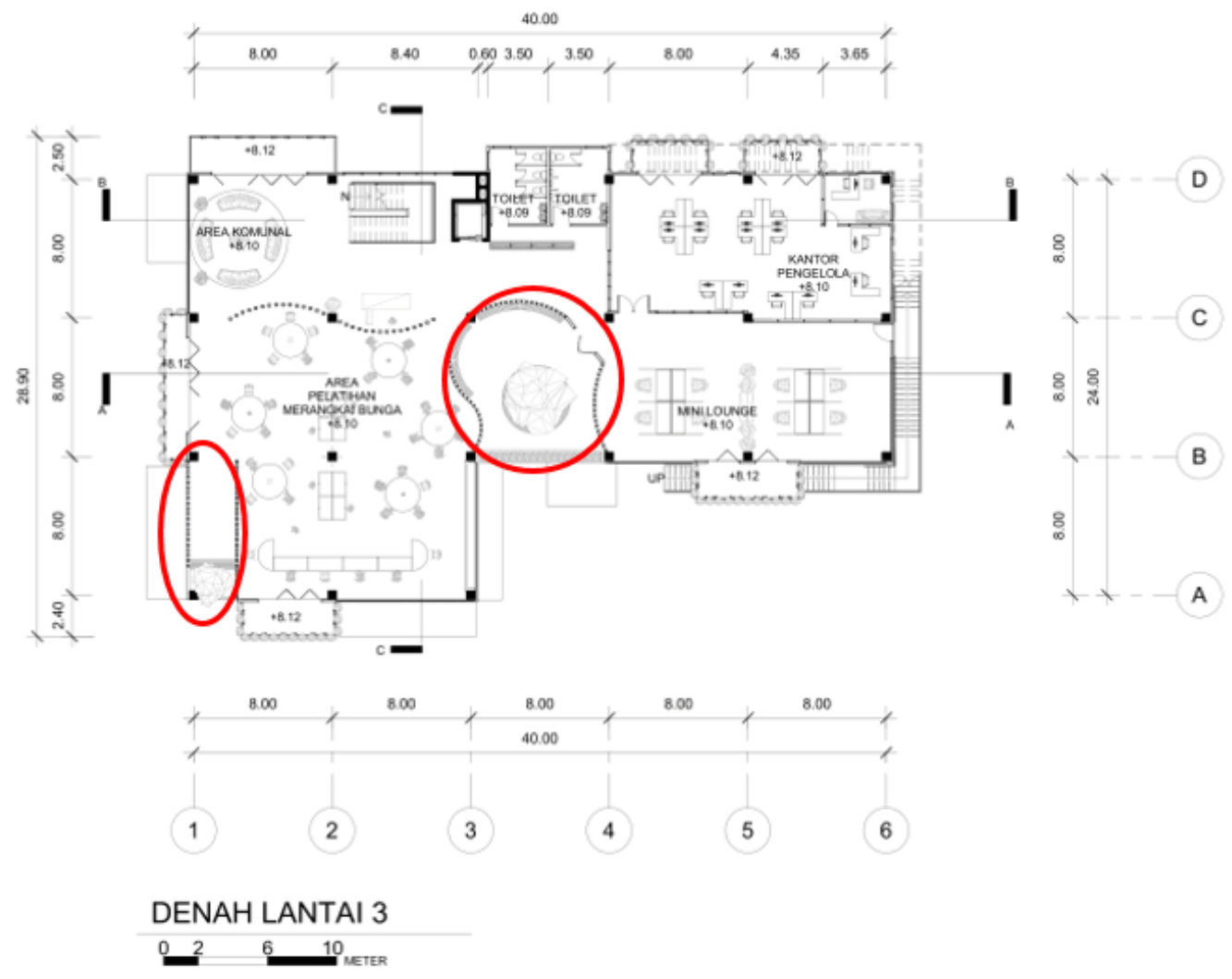

Gambar 12. Letak ruang terbuka pada denah lantai 3 Sumber: Penulis, 2020 

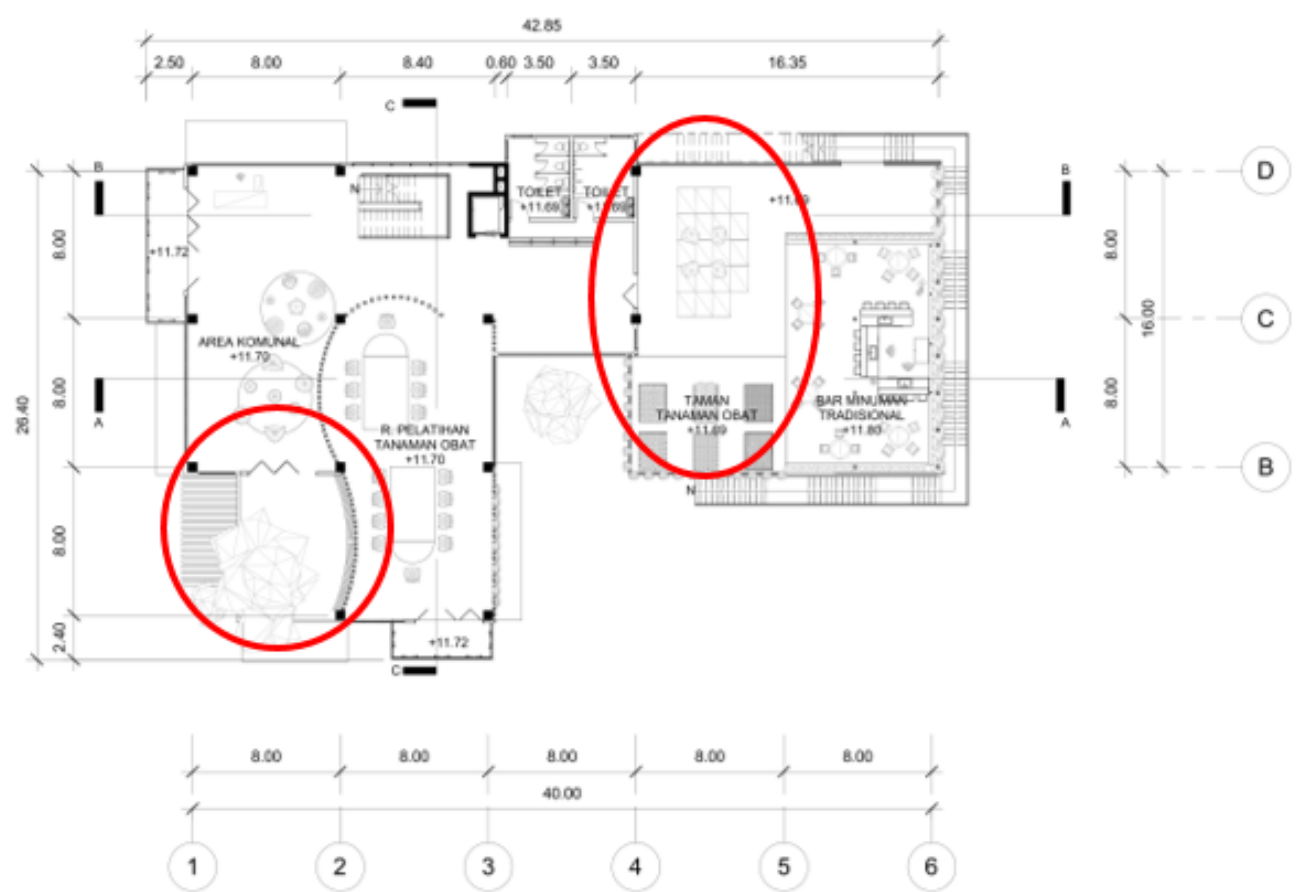

\section{DENAH LANTAI 4}

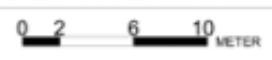

Gambar 13. Letak ruang terbuka pada denah lantai 4 Sumber: Penulis, 2020

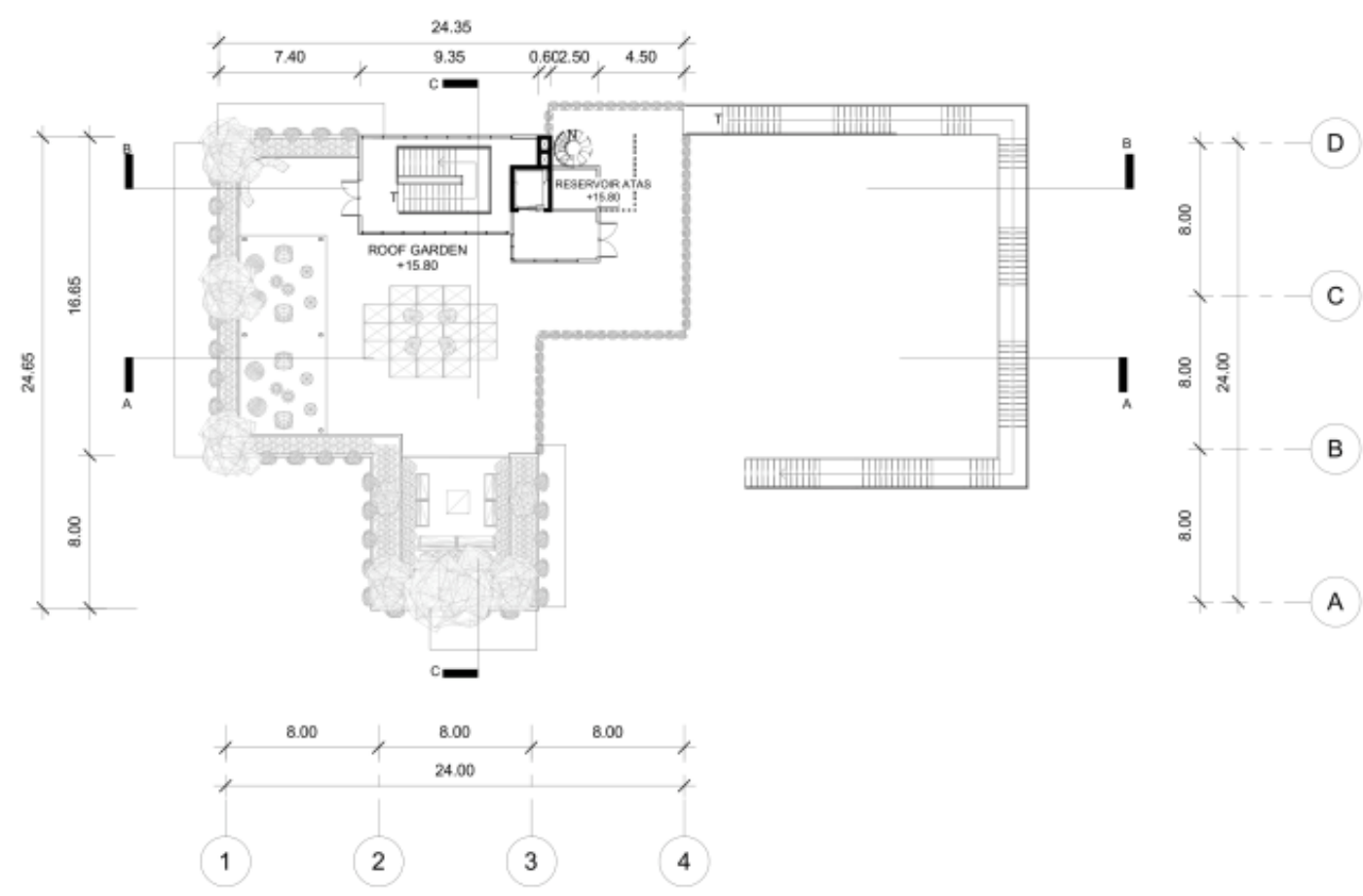

\section{DENAH ATAP}

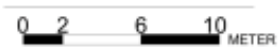

Gambar 14. Denah roof garden

Sumber: Penulis, 2020 
Ide desain yang ketiga adalah menciptakan bentuk yang dinamis agar bangunan lebih mencerminkan sebagai ruang komunitas. Dalam penerapannya, pada bangunan dirancang balkon-balkon kecil yang berguna sebagai ruang terbuka serta memberikan tampak bangunan yang lebih dinamis dan tidak kaku.

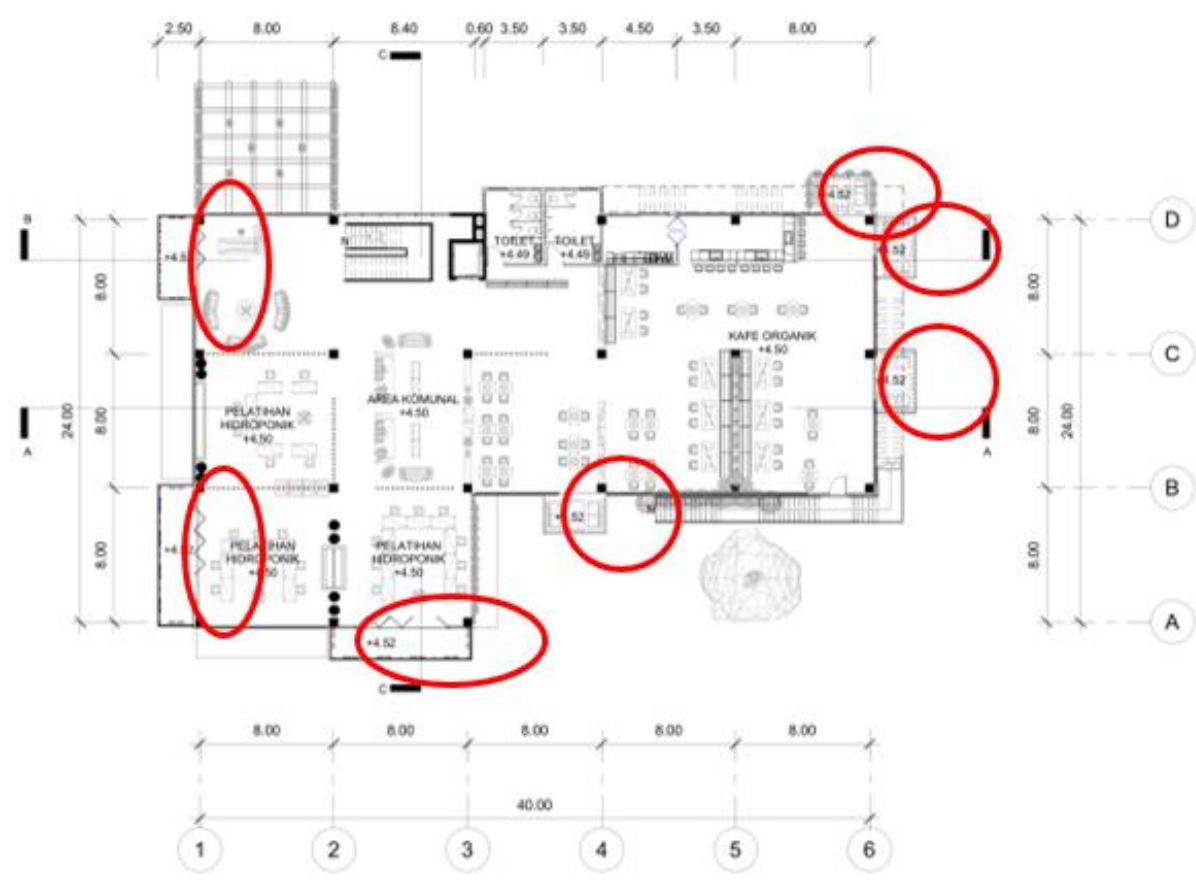

\section{DENAH LANTAI 2}

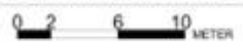

Gambar 15. Letak balkon pada denah lantai 2

Sumber: Penulis, 2020

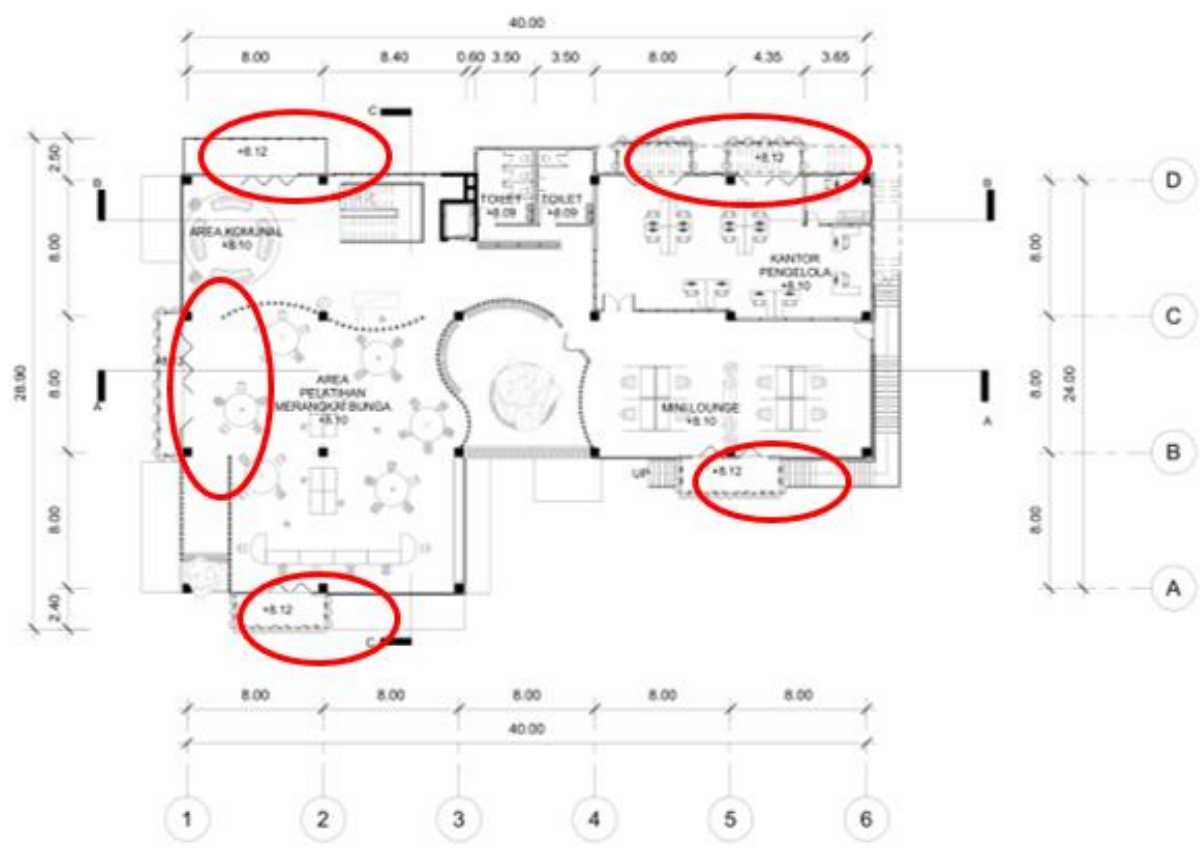

DENAH LANTAI 3

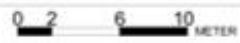

Gambar 16. Letak balkon pada denah lantai 3 Sumber: Penulis, 2020 


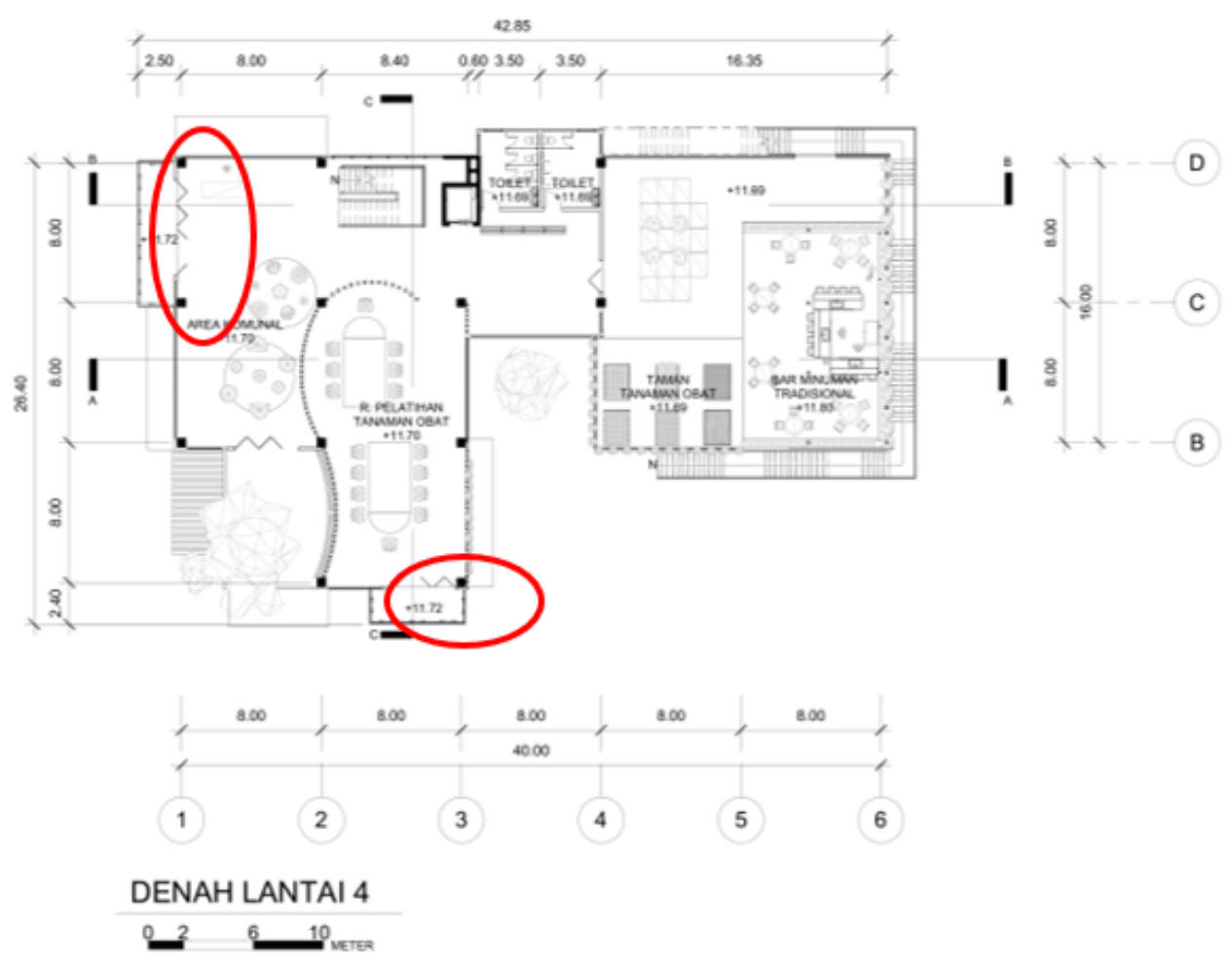

Gambar 17. Letak balkon pada denah lantai 4 Sumber: Penulis, 2020

\section{KESIMPULAN DAN SARAN}

Semakin berkurangnya tingkat interaksi secara langsung antar manusia jika terus dibiarkan akan mengakibatkan manusia bersikap semakin individualis dan tidak peduli terhadap orang lain yang ada di sekitarnya. Untuk mencegah hal itu, salah satu hal yang dibutuhkan adalah ruang komunitas yang menjadi titik temu di mana orang dapat bertemu secara langsung dengan orang lain baik untuk berkumpul maupun bertukar pikiran. Selain itu, di masa depan tanaman merupakan salah satu hal yang sangat mempengaruhi kehidupan manusia. Oleh sebab itu, dirancang ruang komunitas yang berbasis pada tanaman.

\section{REFERENSI}

Crow, G., \& Allan, G. (1994). Community Life: An Introduction to Local Social Relations. Harlow:

Pearson education.

Ginintasasi, R. (2017). Interaksi Sosial. Jurusan Psikologi Universitas Pendidikan Indonesia.

Google, 2020, Google Maps, diunduh 05 Januari 2021, https://www.google.com/maps

Hillery, G. J. (1955). Definition of Community: Areas of Agreement. Rural Sociology, 20: $111-$

122.

Kertajaya, H. (2008). Arti Komunitas. Jakarta: Gramedia Pustaka.

Partowisastro, R. (2003). Perbandingan Konsep Diri dan Interaksi Sosial Anak-Anak Remaja

WNI Asli dengan Keturunan Tionghua. Yogyakarta: Fakultas Psikologi UGM.

Pemerintah DKI Jakarta, 2020, Jakarta Satu, diunduh 05 Januari 2021,

https://jakartasatu.jakarta.go.id/portal/apps/sites/\#/public

Soekanto, S. (2000). Sosiologi Suatu Pengantar. Jakarta: PT. Raja Grafindo Persada.

Wates, N., \& Knevitt, C. (1987). Community Architecture: How People are Creating Their Own

Environment. London: Routledge. 
